\title{
Smart Helmet using GPS and GSM Modem
}

\author{
Ashwin M, Yashwanth Gowda S
}

\begin{abstract}
-motorbike accidents are happening with alarming frequency and the range of fatalities is also increasing each day. currently there are no technological interventions getting used to prevent such occasions. This paper proposes a clever Helmet machine the usage of GPS and GSM modules as a way to assist in avoiding such situations to a large volume. The clever helmet has a module to discover whether the rider is sporting the helmet and also analyses the breath of the rider to test for intake of alcohol. The rider will not be capable of start the automobile if the rider is inebriated and isn't always wearing the helmet. The present day situation is to take measures for the bike handlers who could unfastened their lives due to alcohol intake and for now not wearing the helmet. in order to overcome the death price of the humans due to this, we can use "clever helmet which has automated Alcohol detection and twist of fate detecting technique in it”.
\end{abstract}

Index phrases-GSM Modem, GPS Receiver, Alcohol Sensor, Vibrator Sensor, RF Encoder, RF Transmitter, DPDT delay.

\section{INTRODUCTION}

nowadays, motorcycle has emerge as a totally commonplace mode of delivery for character riders. motorbike offers the liberty and flexibility for the riders to transport everywhere they want and at any time. Riders do now not need to be depending on the general public transportation services, which in lots of towns and nations are extremely unreliable. but, motorbike riding has its own dangers concerned, specially when the rider does now not follow the regulations and do now not take the necessary precautions to avoid unlucky situations, that may result in injuries, which can be occasionally deadly. despite the fact that there are legal guidelines related to secure operation of motorcycles most of the instances the policies aren't accompanied. The traffic police which is chargeable for implementing the legal guidelines on the riders locate it very difficult due to speedy boom inside the quantity of bike riders and no longer having ok manpower to reveal the scenario. In March 2015 there were 154 million registered wheelers running on Indian roads [1]. In such situations technological improvements can drastically assist the traffic police in preserving the guidelines on the street. there are many novel ideas proposed to tackle this trouble. Cameras can be established at essential traffic junctions to reveal the site visitors as well as to perceive the visitors violators and problem suitable fines to such riders [2]. apart from jumping of site visitors junctions or comparable violations of the traffic legal guidelines one most important difficulty with riders isn't always wearing the helmet while operating a motorcycle and every other essential hassle is of under the influence of alcohol using mainly in the course of night $[3-10]$. right here in this challenge the authors are offering a singular concept of embedding sensors in the bike and the helmet to research the breath and the carrying of the helmet via the rider. If the rider is not following the regulations the bike will not begin.

The purpose of the task is to provide reliability and soundness on the helmet to the bikers against road accidents. A clever Helmet is revolutionary recommendation which make motor cycle riding safer than before, this is done the usage of GSM Modem and GPS receiver era. the only more supremacy of this project is to recognize the alcohol level of drunken motorcyclist who is sitting at the bike. An embedded kit or an embedded gadget which includes microcontroller, RF decoder and sensors, is integrated inside the helmet which screen whether or not the biker is drunk or not and additionally a few sensors to test whether or not the biker has worn the helmet or no longer. The alcohol level is determined and displayed on a liquid crystal display show. every time the alcohol is detected through the alcohol sensor in the helmet, the car gained't start and buzzer is blown and the respective authorized human beings gets the notification. In these days's global cars injuries are one of the principal reasons for increase inside the dying. This loss of life charge may be decreased with the aid of forwarding a message and the vicinity of the accident to the victim's own family and worried government who can take the important action in a timely manner. in many cases the put off in giving the best clinical treatment is the predominant motive of death after an twist of fate. on this challenge a GPS and a GSM module is embedded within the helmet that could offer the exact vicinity of the twist of fate.

\section{OPERATIONAL PRECEPT}

The principle of operation is quite simple. If the biker had consumed the alcohol, the alcohol sensor placed close to the the front quit of the helmet senses the alcohol and don't allow the biker to start the motorbike. the second motive is whilst the biker meet with an coincidence the vibrator sensor in the motorcycle gets the signal send a message and the vicinity of twist of fate to the own family members. The $1 / 3$ reason is wherein the bike won't prompt till the helmet is worn while $\mathrm{RF}$ decoder sends records to the microcontroller which permits the biker to start the bike.
Revised Version Manuscript Received on 10, September 2019.

Ashwin M, Department of Electrical and Electronics Engineering, Vidyavardhaka College of Engineering, Mysuru, Karnataka 570002. (Email: ashwinplaymaket1999@gmail.com)

Yashwanth Gowda S, Department of Electrical and Electronics Engineering, Vidyavardhaka College of Engineering, Mysuru, Karnataka 570002 (Email: yashwanthgowda.mys@gmail.com) 
Functional Schematic Diagram: Vehicle Unit

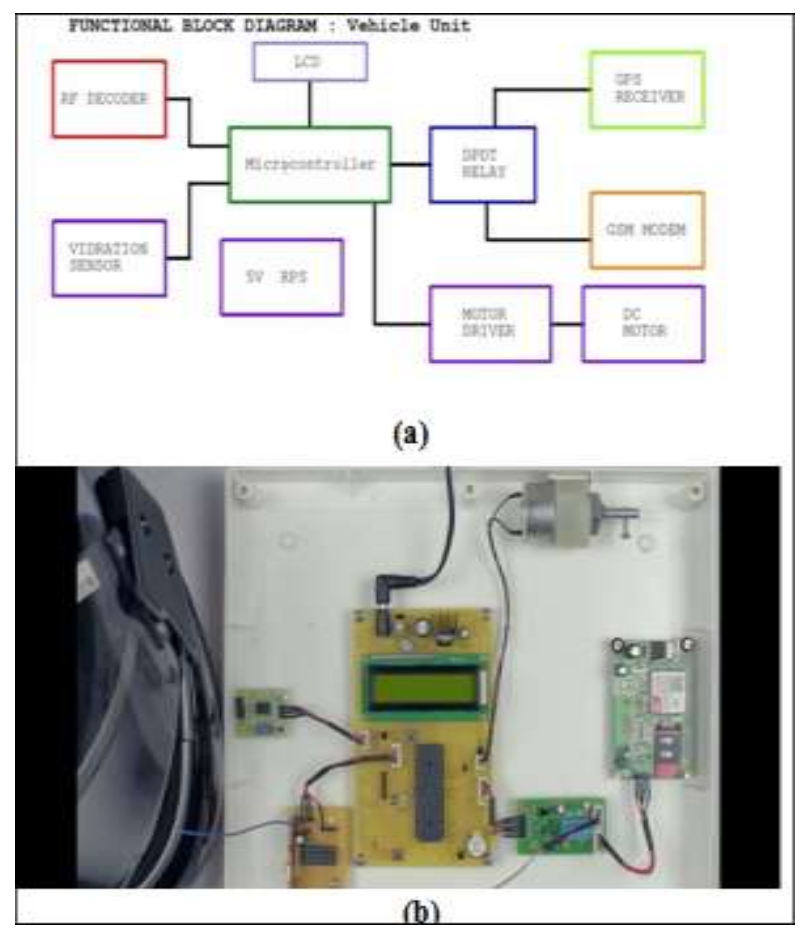

Fig. 1 (a) Schematic diagram of vehicle unit which incorporate GPS Receiver and GSM Modem. (b)

Hardware components which is connected to the vehicle in the vehicle unit.

The Fig.1 (a) shows the schematic diagram of the vehicle unit, it has a microcontroller which helps in every process of operation.

It has a vibration sensor to detect accident that occurs. RF decoder is connected to helmet to receive the data from the helmet. It consists of $16 \times 2 \mathrm{LCD}$ to display the various information. DPDT relay is used to switch to GSM.

\section{$R F$ decoder:}

The capability of this device is, it can receive information from a long distance and it can be from the space too. And it has a DC driver which is used to drive the DC motor which acts as the vehicle or bike in this project.

The hardware part of the helmet mainly consists of ATmega32 Microcontroller running at $8 \mathrm{MHz}$ clock and operates at $5 \mathrm{~V}$ power. It has a RF decoder which is connected to GPIO (general purpose input/output) pins. Microcontroller consists of interrupt pins and these pins connects to the helmet switch and the vibration sensor. The $16 \times 2$ LCD is configured to work on 4bit mode and is connected to the port $\mathrm{C}$ of microcontroller.

The LED and the buzzers are used for indication when there any uncertainties occur. The GPS and GSM Modem is connected to DPDT delay switch which in turn is connected from GPIO pins. The input port of the system is $9 \mathrm{~V}$ since hardware requires $5 \mathrm{~V}$ supply the $9 \mathrm{~V}$ is converted to $5 \mathrm{~V}$ using LM7805 Regulator.

As soon as the microcontroller is powered, the peripherals such as GPIO, TIMER are initialized. The RF decoder and the vibrator sensor is monitored by the microcontroller. The vehicle do not start because not wearing the helmet, once the helmet is worn the RF encoder sends the signal to the microcontroller and engine gets started.

\section{Functional Schematic Diagram: Helmet Unit}

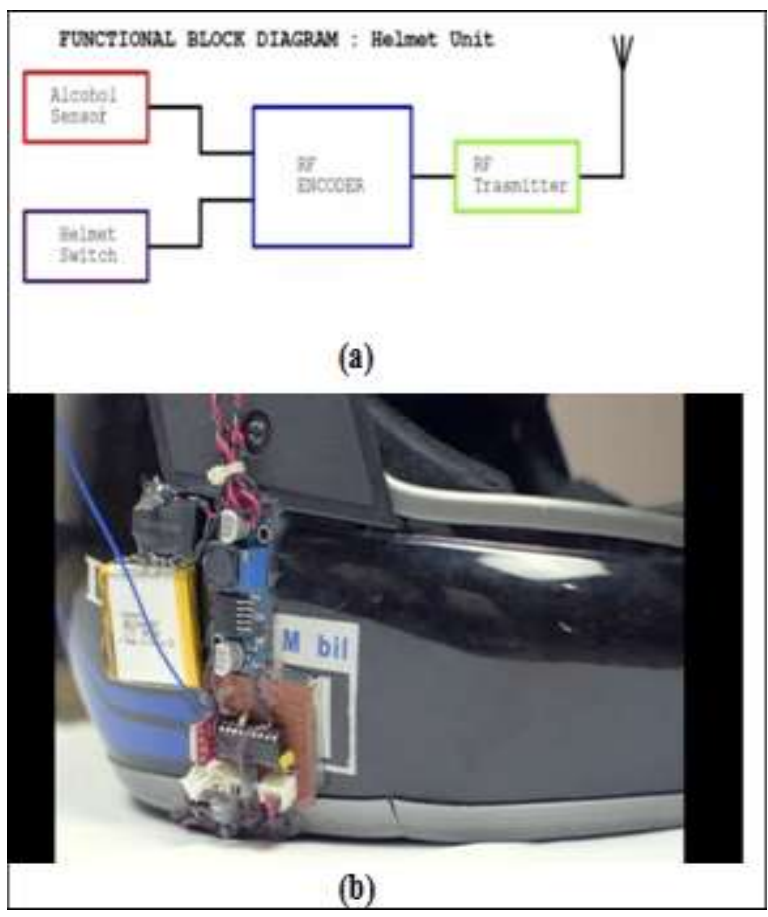

Fig. 2 (a) Schematic diagram of Helmet unit incorporating an Alcohol sensor and a Helmet switch. (b) Hardware components attached to the helmet.

Fig.2 shows the helmet unit, it has an alcohol sensor which senses if the biker is alcoholic and a helmet switch which interprets the message to the LCD display saying that the biker has not worn the helmet. The bike will not turn on until the biker wears the helmet.

The helmet consists of $3.6 \mathrm{~V}$ lithium battery and a battery charger. It also have A HT12E encoder, $434 \mathrm{MHz}$ RF Transmitter, Alcohol sensor and a Helmet switch and a boost Convertor.

In HT12E encoder the $434 \mathrm{MHz}$ RF Transmitter is affixed to the encoder the alcohol sensor is bridged to data pin of the encoder and the helmet switch is attached to enable pin of the encoder. The input ports helmet is $3.7 \mathrm{~V}$ but it regulated to 5 $\mathrm{V}$ by using a boost convertor.

\section{RESULTS}

The Smart helmet system was tested and the resultant output was studied. Once the system is tested it can be integrated in a helmet and the bike. The first part was to test whether the biker is wearing the helmet. The system does not allow the biker to take vehicle until he has worn the helmet. As soon as the biker wears the system displays a message on the LCD screen saying that HELMET WEARED as shown in the fig 3.

Whenever the biker has consumed the alcohol the system does not allow vehicle to start and will send the message ALCOHOL CONSUMED in LCD display as shown in fig. 4 


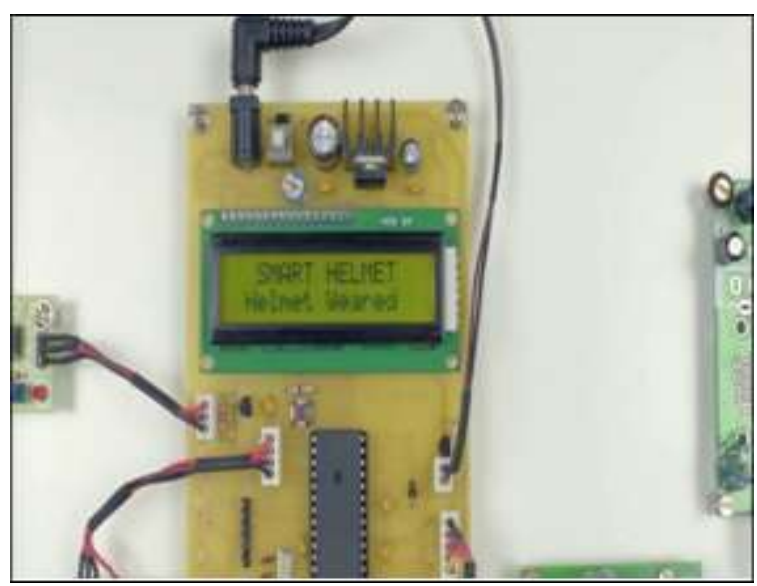

Fig. 3 LCD displaying the message of helmet worn.

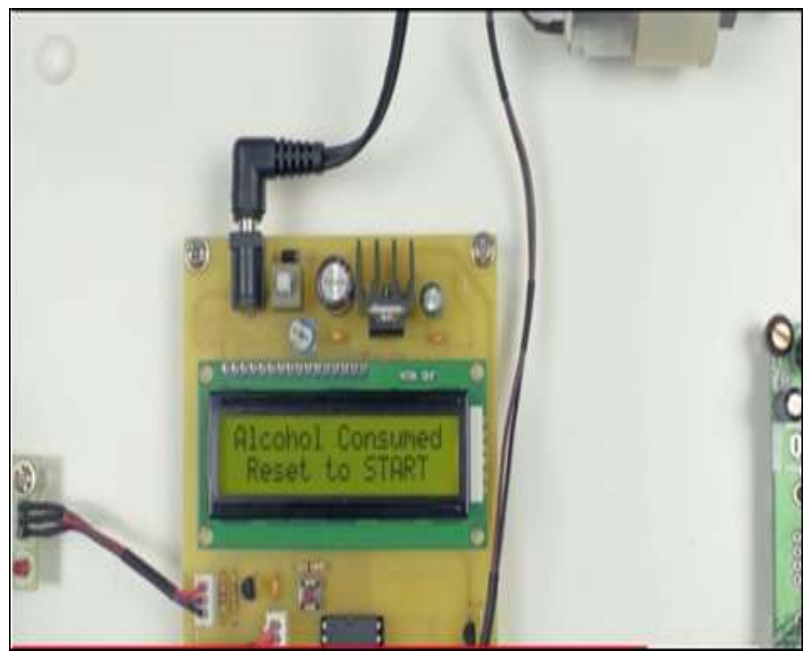

Fig. 4 Display showing the message that biker has consumed alcohol.

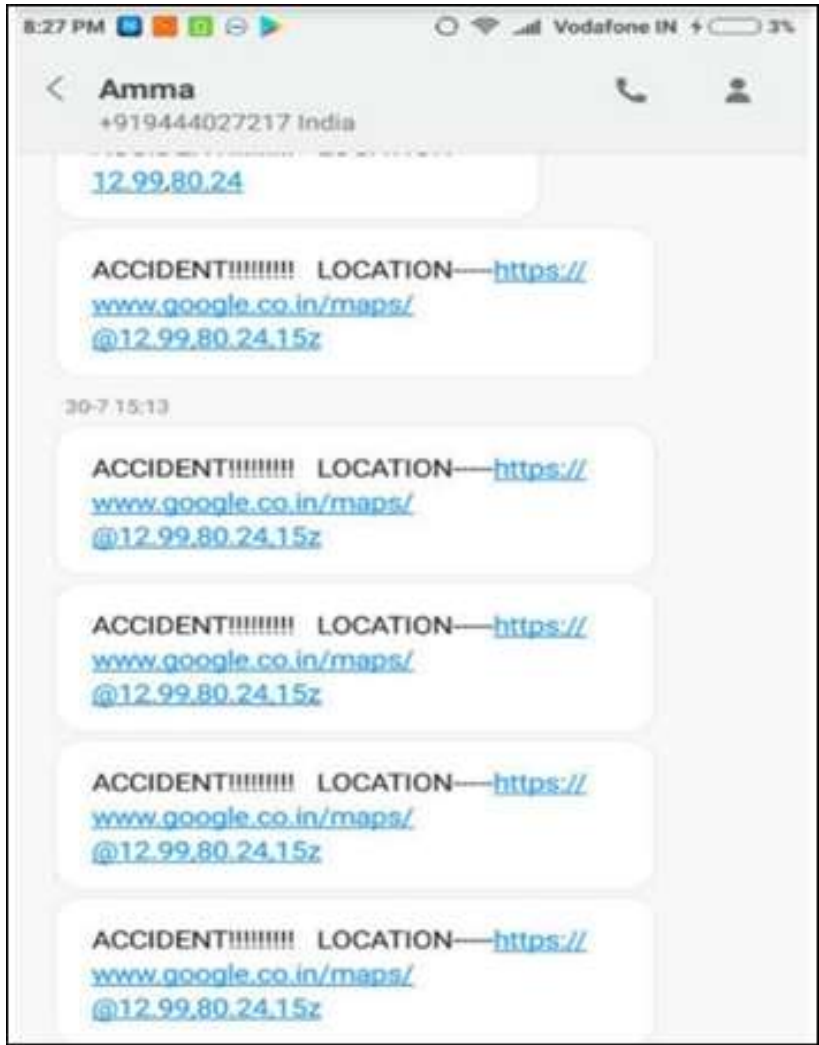

Fig. 5 Message received on a GSM mobile about the accident and its location.
Whenever biker meet with an accident the vibrator sensor senses it and sends the message to the number that is configured saying about the accident and sending a link which gives the location of the accident as shown in fig. 5 .

\section{CONCLUSION}

This paper pursuits on the blessings of the society by means of decreasing the dying fee brought on because of not wearing the helmet and riding motorcycle by way of consuming alcohol and supplying the information to circle of relatives about the accident and vicinity of the identical. A clever helmet system is evolved which has embedded systems so that you can screen whether or not the rider is sporting a helmet and if the rider has fed on alcohol. In both of the instances the motorcycle would not start and the rider would now not be capable of use it. this is a preventive approach to reduce injuries and fatalities on the road. This system additionally has a GPS and GSM unit which will ship a message and the region of the motorbike to the circle of relatives individuals of the motorbike rider inside the unlucky event of an twist of fate. this may help in providing well timed assist to the rider and decrease the fatalities.

\section{ACKNOWLEDGEMENT}

The authors specific gratitude toward the assistance furnished through Accendere understanding management services Pvt Ltd for the expert advice.

\section{REFERENCES}

1. Hasan Mehdi Naqvi \& Geetam Tiwari, "factors contributing to motorcycle fatal crashes on national Highways in India", global magazine of damage manipulate and protection promotion, vol 25 , no 3 , pp 319-328, 2018.

2. Khaled Shaaban and Anurag Pande, "evaluation of red-mild digicam enforcement using site visitors violations", magazine of traffic and Transportation Engineering, vol five, \#1, pp 66-seventy two, 2018.

3. R. Silva, okay. Aires, and R. Veras, "Helmet detection on motorcyclists using picture descriptors and classifiers," twenty seventh SIBGRAPI convention on snap shots styles and photographs, pp. 141-148, 2014.

4. Sayan Tapadar, Shinjini Ray, Himadri Nath Saha, Arnab Kumar Saha, and Robin Karlose, "twist of fate and Alcohol Detection in Bluetooth enabled clever Helmets for Motorbikes", 8th Annual Computing and conversation Workshop and convention (CCWC), pp 584 - 590, 2018.

5. Sreenithy Chandran, Sneha Chandrasekar, N Edna Elizabeth, "Konnect: an internet of factors (IoT) based totally clever helmet for coincidence detection and notification", IEEE Annual India convention (INDICON), 2016

6. Jie Li, Huanming Liu, Tianzheng Wang, Min Jiang, Kang Li Xiaoguang Zhao, Shuai Wang, "safety Helmet carrying Detection primarily based on photo Processing and machine mastering", 9th international conference on superior Computational Intelligence (ICACI), pp 201 205, 2017.

7. R. Rathinakumar and D. Manivannan "wi-fi accident information the use of GPS and GSM", research journal of implemented Sciences, Engineering and generation, Vol 
four, no 18, pp 3323 - 3326, 2012

8. Mohd Khairul Afiq Mohd Rasli, Nina Korlina Madzhi, Juliana Johari, "clever helmet with sensors for coincidence prevention." global conference on electric, Electronics and device Engineering (ICEESE), pp 21 - 26, 2013

9. Manjesh N, Sudarshan Raj, "smart Helmet the use of GSM \& GPS generation for twist of fate Detection and Reporting gadget”, global journal of electrical and Electronics studies, Vol 2, issue 4, pp 122 - 127, 2014.

10. J. Vijay, B. Saritha, B. Priyadharshini, S. Deepeka, R. Laxmi, "Drunken drive safety system", worldwide magazine of medical \& Engineering research, Vol 2, problem 12, pp 1 - four, 2011. 